\title{
Building an effective and enduring prevention
} system

\section{Ben J Smitha,b,c}

a Associate Editor, Health Promotion and Prevention, Public Health Research \& Practice

b School of Public Health, University of Sydney, NSW, Australia

${ }^{c}$ Corresponding author: ben.smith@sydney.edu.au

\section{Article history}

Publication date: June 2021

Citation: Smith BJ. Building an effective and enduring prevention system. Public Health Res Pract. 2021;31(2):e3122106. https://doi. org/10.17061/phrp3122106
The coronavirus disease 2019 (COVID-19) health emergency exceeds anything that Australia has faced in the past half century, certainly if gauged by social upheaval and sweeping policy intervention. Much is now being written about the success of the national response to this threat (notwithstanding some missteps), with public health leaders taking this opportunity to highlight the profound benefits of concerted, evidenceinformed prevention. ${ }^{1,2}$ Although we are yet to see the lasting opportunities that will emerge from the COVID-19 crisis, it may be that one of these is a deeper understanding that a stronger investment in public health policy and infrastructure is vital to the nation's interests.

One reason to hope that we may be on the cusp of a significant pivot towards prevention in Australia is the arrival in 2021 of a remarkably prescient policy document, the draft National Preventive Health Strategy. ${ }^{3}$ The strategy, which has been under development since 2019, represents a comprehensive, best-practice statement of the aims, principles and enablers for prevention policy and practice. It has been widely endorsed by public health organisations. ${ }^{4,5}$ The core understandings and essential pillars for action set down in this document deserve to be highlighted. So too, do challenges revealed by Australia's past efforts to implement and institutionalise prevention, which if not addressed, will undermine our ability to realise the health and social gains promised by the strategy.

\section{Foundations and priorities for prevention planning}

From the outset, the strategy presents a compelling logic for a stronger engagement in prevention, not only to reduce avoidable morbidity and mortality, but also to meet national aspirations for labour force participation, economic productivity and the wellbeing of future generations. Prevention, therefore, represents a strategic and long-term investment that is tied to many of the nation's interests.

The strategy is explicit about how prevention should be understood, the scope for action, and the multiple agencies and stakeholders that should be involved in this work. While it is acknowledged that individual attributes and behaviours play a role in determining health status, it is the social, environmental, cultural, structural, economic and commercial conditions in which people live - the causes of the causes - that are identified as having a more fundamental impact. Cross-sectoral engagement in prevention, and 
the adoption of a 'health in all policies' approach ${ }^{6}$, are therefore essential.

There is a fundamental orientation within the draft strategy towards the ongoing disparities in health status generated by differential exposure to the deteminants of health, particularly among our First Nations peoples. Reducing health inequities is positioned as a foremost aim, with recognition that this will require the combination of universal and selective prevention strategies to meet the health needs experienced by priority groups.

An evidence-based and ethically informed perspective is evident throughout the strategy, but it is the attention to the requirements for successful action that is its more remarkable feature. The need for a marked increase in government investment in prevention and health promotion, from the current level of $1.5 \%$ of health expenditure to $5 \%$, is situated as one of its four primary aims. A framework for action is given, encompassing: 1) mobilising a prevention system; 2) boosting action in focus areas; and 3) continuing strong foundations. Public health advocates and practitioners will be heartened by the emphasis given to leadership, governance structures supporting cross-portfolio action, and development of a capable public health workforce. Having seen the disruptive effects of previous waves of prevention policy making upon existing initiatives, they will also be relieved to see the intention to use and build on public health infrastructure and programs.

The stipulation of outcomes targets, including data sources for monitoring these, is notable. If adopted, these will signal genuine commitment to and accountability for achieving the aims that are set down and, it can be hoped, undertaking the necessary expansion and strengthening of the prevention system to achieve these.

\section{Implementing and institutionalising prevention strategies}

The draft National Preventive Health Strategy includes many promising and timely elements, reflective of the evidence, expert insight and stakeholder input that have been brought to bear on its development. Past experience shows, however, that even with clear directions and solid foundations the more important (and complex) phase is the one that follows this, involving planning, partnership development, coordination and resource allocation to implement effective action. The challenges that we have historically faced in doing this are well stated in the strategy:

"While Australia has a history of world-leading prevention programs, our approach to prevention is often disjointed, not sustained and does not effectively build on locally successful programs to deliver national change." (p 31)

The strategy proposes that a "Blueprint for Action" be developed, to mobilise the prevention system and leverage existing health infrastructure to meet the targets that have been stipulated. It is valuable, therefore, to review important (and often neglected) planning and administrative issues that will affect the strength of this implementation effort.

\section{Prevention management expertise}

Because the design and delivery of policies and programs will be determined by the capacities of those overseeing these, it will be vital to recruit personnel who have track records in the management of complex, crossjurisdictional prevention strategies to leadership positions. Further, there should be sufficient staffing levels in the national agency with primary carriage of the strategy to ensure that comprehensive implementation planning and management is undertaken. ${ }^{7}$

\section{Policy and program specifications}

Given the need to work with diverse sectors and levels of government, there is a high risk that inconsistencies in program management knowledge and skills will have a bearing on the quality and effectiveness of strategies. This risk would be mitigated by the development of criteria for program design and management to guide both lead agencies and funding recipients, addressing issues such as the use of evidence and theory in planning, incorporating equity considerations into strategy selection, and actions to build sustainability. Development of networks has been found to enable sharing of knowledge and evidence in prevention focus areas $^{8}$, and can facilitate improved standards in policy and practice.

\section{Regional workforce capacity}

The availability of a capable public health workforce is a critical component of the prevention system, particularly at the regional level, which the strategy acknowledges to be "at the heart of the health response" (p 34). ${ }^{3}$ However, the appointment of personnel without appropriate training in public health or health promotion, the prevalence of small teams dedicated to prevention, and staff turnover due to lack of role clarity and/or funding stability, has been found to significantly impair the quality and continuity of prevention programs in Australia. ${ }^{9,10}$ This highlights the need for public health agencies to review criteria for staff selection, the size and structure of teams, duration of appointments, remuneration, training and opportunities for career advancement, which will affect the composition and continuity of the prevention workforce at the regional level.

\section{Enablers for evaluation}

Evaluation is widely understood to be necessary for improving the delivery, impact and sustainability of prevention strategies, however there is probably no other area of public health where the gap between what is espoused and practised is greater. A study of prevention 
agencies across Australia found that it is not only practitioner attitudes and skills, but also organisational factors (e.g. leadership, access to specialised support), and wider systemic factors (e.g. reporting requirements, program timeframes), that determine evaluation practice and quality. ${ }^{11,12}$ Consequently, evaluation must be comprehensively planned for and supported across multiple levels of the prevention system if it is to provide the value that is hoped for.

\section{A window of opportunity}

The conjunction of heightened awareness about the societal importance of public health, and the arrival of the finalised National Preventive Health Strategy to catalyse and guide a greater investment in prevention, could bring about a rebalancing within Australia's health system in the coming decade. We can hope that our national leaders, and the broad constituency of stakeholders necessary to move this work forward, will give this strategy the support it deserves. Learning from the successes and shortcomings of past decades of prevention policy and programs in Australia, it can also be hoped that we grasp this opportunity to build the capacity and durability of the prevention system required to tackle our current and future health priorities.

\section{Acknowledgements}

Thank you to Mark Harris who reviewed this manuscript and provided input into the final draft.

The Sax Institute, which is the publisher of Public Health Research \& Practice, has had a role as a consultant to the Australian Government Department of Health in the development of the National Preventive Health Strategy. The journal's Editor-in-Chief, Don Nutbeam, also had an advisory role as a then senior advisor to the Sax Institute.

\section{Peer review and provenance}

Internally peer reviewed, invited.

\section{Competing interests}

None declared.

\section{Author contributions}

BS is the sole author.

\section{References}

1. Slevin T. The future for preventive health in Australia. Health Voices. Journal of the Consumers Health Forum of Australia. 2020;26(1).
2. Wilson A. 10 lessons the prevention community can take from Australia's COVID-19 response. Sydney: The Australian Prevention Partnership Centre; 2021 Mar 29 [cited 2021 May 15]. Available from: preventioncentre. org.au/blog/10-lessons-the-prevention-community-cantake-from-australias-covid-19-response/

3. Australian Government Department of Health. Draft National Preventive Health Strategy 2021-2030. Canberra: Commonwealth of Australia; 2021 [cited 2021 May 15]. Available from: consultations.health.gov. au/national-preventive-health-taskforce/draft-nationalpreventive-health-strategy/supporting_documents/ Draft\%20NPHS\%20March\%202021.pdf

4. Public Health Association of Australia. Media release: National Preventive Health Strategy could transform Australian health - if action is taken. Canberra: PHAA; 2021 [cited 2021 May 15]. Available from: www.phaa.net. au/documents/item/5077

5. Australian Chronic Disease Prevention Alliance. Response to National Preventive Health Strategy. ACDPA; 2021 [cited 2021 May 15]. Available from: b282daf8aa1b-4fbd-8feb-aaa0e154e735.filesusr.com/ugd/6eeba7 120e5829f3f14abeb16f91bff0642e37.pdf

6. World Health Organisation. Helsinki statement on health in all policies. Geneva: WHO; 2014 [cited 2021 May 19]. Available from: apps.who.int/iris/bitstream/ handle/10665/112636/9789241506908_eng.pdf;jsessio nid=2AA22A96313F6EEB85EAA8B5F2CD3133? sequen $\mathrm{ce}=1$

7. Boswell J, Cairney P, St Denny E. The politics of institutionalizing preventive health. Soc Sci Med. 2019;228:202-10.

8. Wutzke S, Morrice E, Benton M, Wilson A. What will it take to improve prevention of chronic diseases in Australia? A case study of two national approaches. Aust Health Review. 2017;41(2):176-81.

9. Bensberg M, Joyce A, Wilson E. Building a prevention system: infrastructure to strengthen health promotion outcomes. Int J Environ Res Public Health. 2021;18(4):1618.

10. Fawkes S, Lin V, Smith J. Public health practice in Australia: The organised effort. NY: Routledge; 2020.

11. Schwarzman J, Bauman A, Gabbe BJ, Rissel C, Shilton T, Smith BJ. The funding, administrative, and policy influences on the evaluation of primary prevention programs in Australia. Prev Sci. 2019;20(6):959-69.

12. Schwarzman J, Bauman A, Gabbe B, Rissel C, Shilton T, Smith BJ. Organizational determinants of evaluation practice in Australian prevention agencies. Health Educ Res. 2018;33(3):243-55.

\section{Copyright: (c) (i) (2) (2)}

(c) 2021 Smith BJ. This article is licensed under the Creative Commons Attribution-NonCommercial-ShareAlike 4.0 International Licence, which allows others to redistribute, adapt and share this work non-commercially provided they attribute the work and any adapted version of it is distributed under the same Creative Commons licence terms. See: www.creativecommons.org/licenses/by-nc-sa/4.0/ 